\title{
Racialized Organizations Theory: A Case Study of Airbnb
}

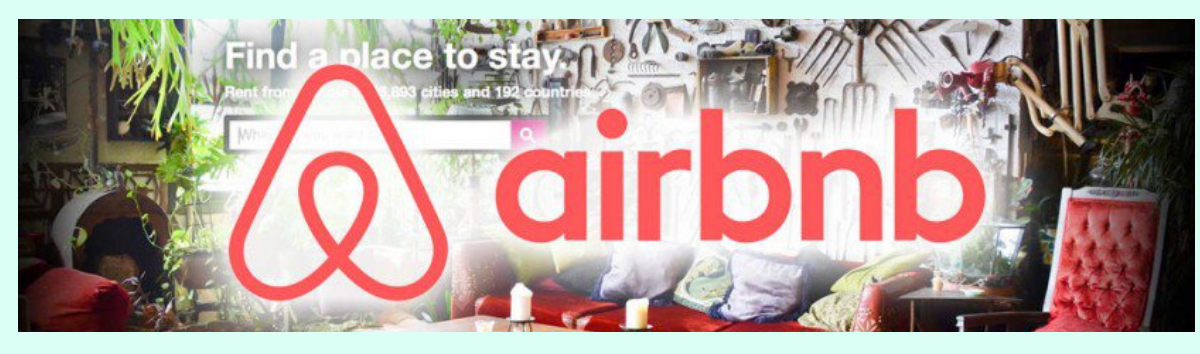

$2 / 26 / 17$

Louise Seamster and Victor Ray University of Tennessee-Knoxville 


\section{Racialized Organizations}

Race scholarship typically focuses on the individual or state level (Omi and Winant 2015, Bonilla-Silva 1997, Golash-Boza 2016)

Organizational theory typically sees race as added to otherwise neutral bureaucratic processes (Perrow 2002, Weber 1978) 


\section{Where is the organization?}
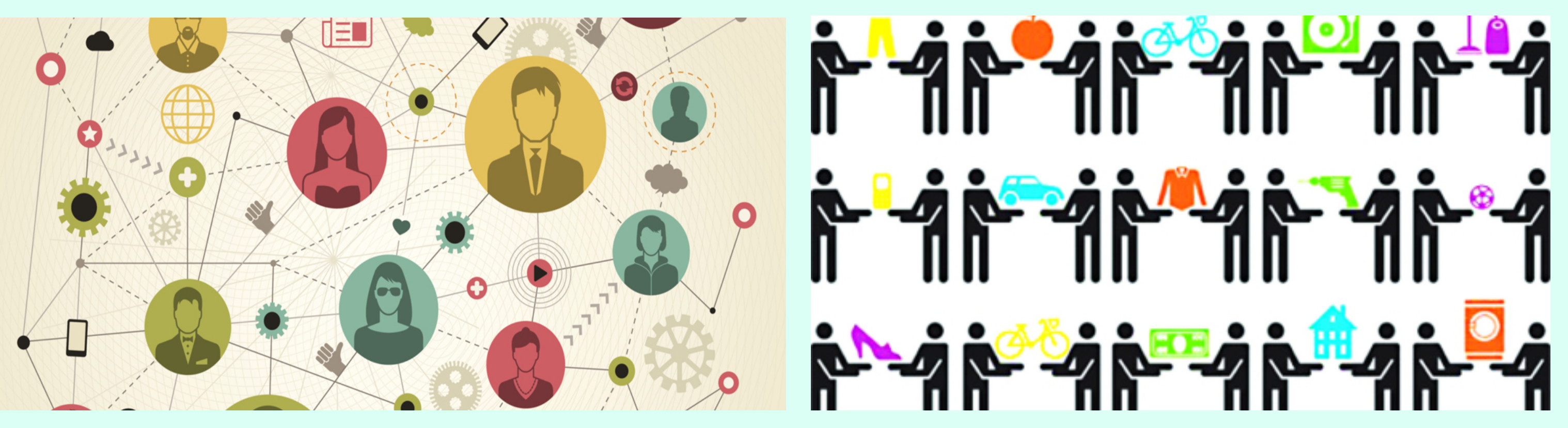


\section{A Case Study of Airbnb}

Individual-level discrimination

Housing and neighborhood effects (gentrification)

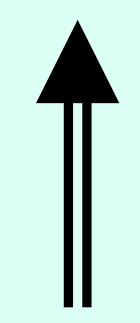

Racialized Organization 


\section{Discrimination against black}

\section{users}

Edelman and Luca, forthcoming: Guests with black names $16 \%$ less likely to receive positive response

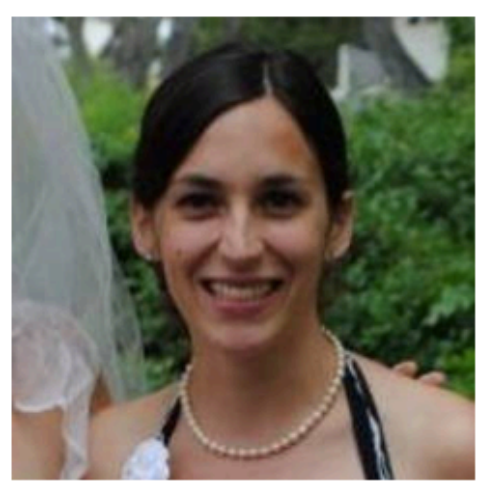

Hey, I'm Louise!

North Carolina, United States · Joined in July 2010

$F_{\text {Report this user }}$

Edit Profile

graduate student in sociology, living in North Carolina

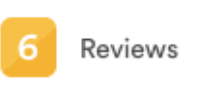

Verified info

Wish Lists (3)

Devan M. Cole @devancole2 - Feb 10

Having your white friend book your Airbnb in Paris because \#AirBnbWhileBlack

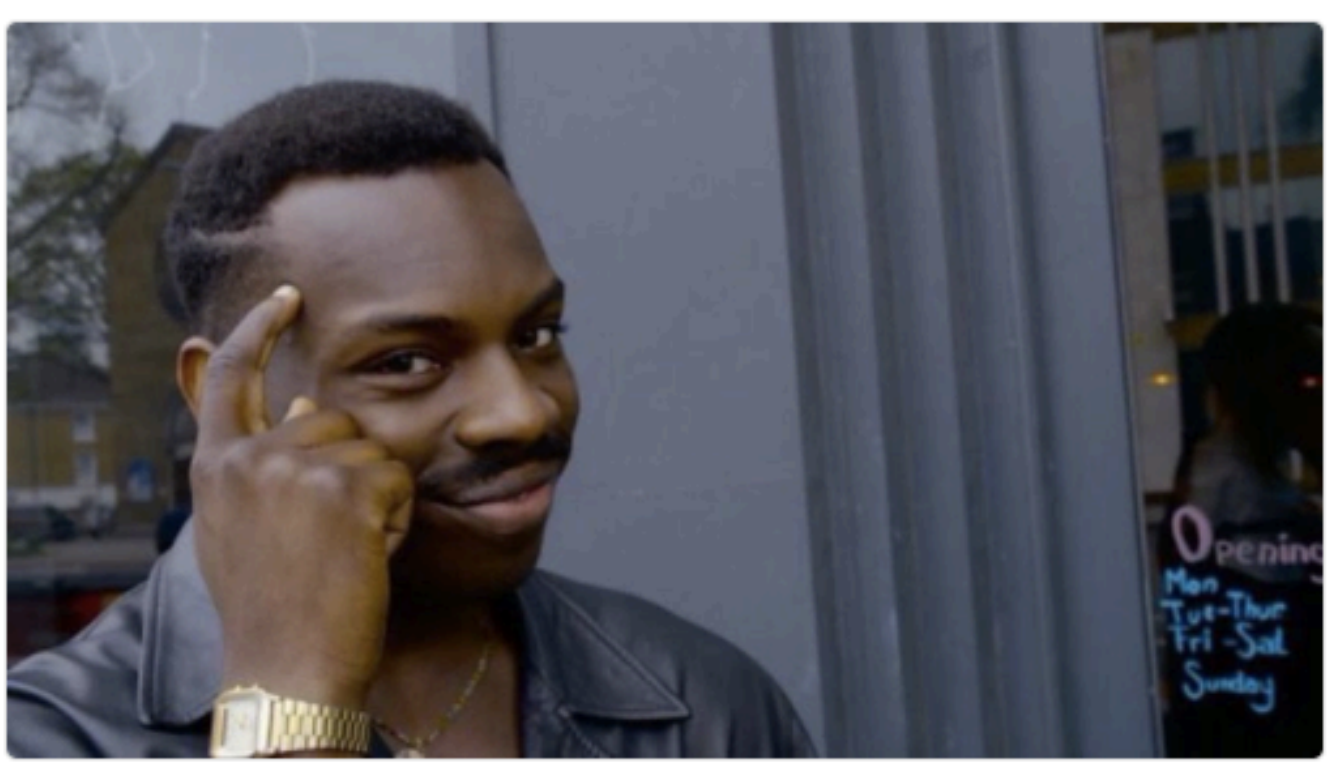

4

ㄴ. 1

17

Carolyn Johnson @cevettejohnson · 7h

\#airbnbwhileblack -- instant booked a place and they told me to leave when they saw me.. and yelled we don't like black people as I exited.

↔ 


\section{Airbnb's 2014 explanation of FHA}

ADA and FHA Compliance | Airbnb Help Center

\section{Does the FHA apply to me as a host?}

The FHA does not apply to all hosts. The FHA contains exemptions for owner-occupied buildings with no more than four units, single-family housing rented without the use of a broker if the private individual owner doesn't own more than three such single-family units at one time, and housing operated by organizations and private clubs that limit occupancy to members and so long as all advertising is nondiscriminatory. There is also a bedand-breakfast or rooming house exemption for properties "containing living quarters occupied or intended to be occupied by no more than four families living independently of each other, if the owner actually maintains and occupies one of such living quarters as his or her residence" which might apply to some hosts' listings.

The FHA also specifically exempts some senior housing facilities and communities from liability for discrimination based on familial status. To qualify for this exemption, such housing must be intended and operated for occupancy by persons 55 years of age or older or intended for and solely occupied by persons 62 years of age or older. This "housing for older persons" exemption does protect against liability for housing discrimination based on race, color, religion, gender, disability or national origin.

However, even if you're exempt from complying with the FHA, it is still illegal to advertise or make any statement that indicates a limitation or preference based on race, color, national origin, religion, sex, familial status, or handicap. This prohibition against discriminatory advertising applies to single-family and owneroccupied housing that is otherwise exempt from the FHA. More information can be found at 24 C.F.R. pt. 100.

Even if the FHA does not apply to you, we expect our hosts to conduct themselves in a respectful manner and work to bridge differences and make accommodations where possible. Through their experiences on Airbnb, we hope that our guests and hosts build meaningful connections with people from all over the globe. 


\section{Airbnb's Diversity}

- Laura Murphy, former head of ACLUWashington DC

- David King III, former head of Diversity Management and Outreach, State Department

- Eric Holder, former US Atty General
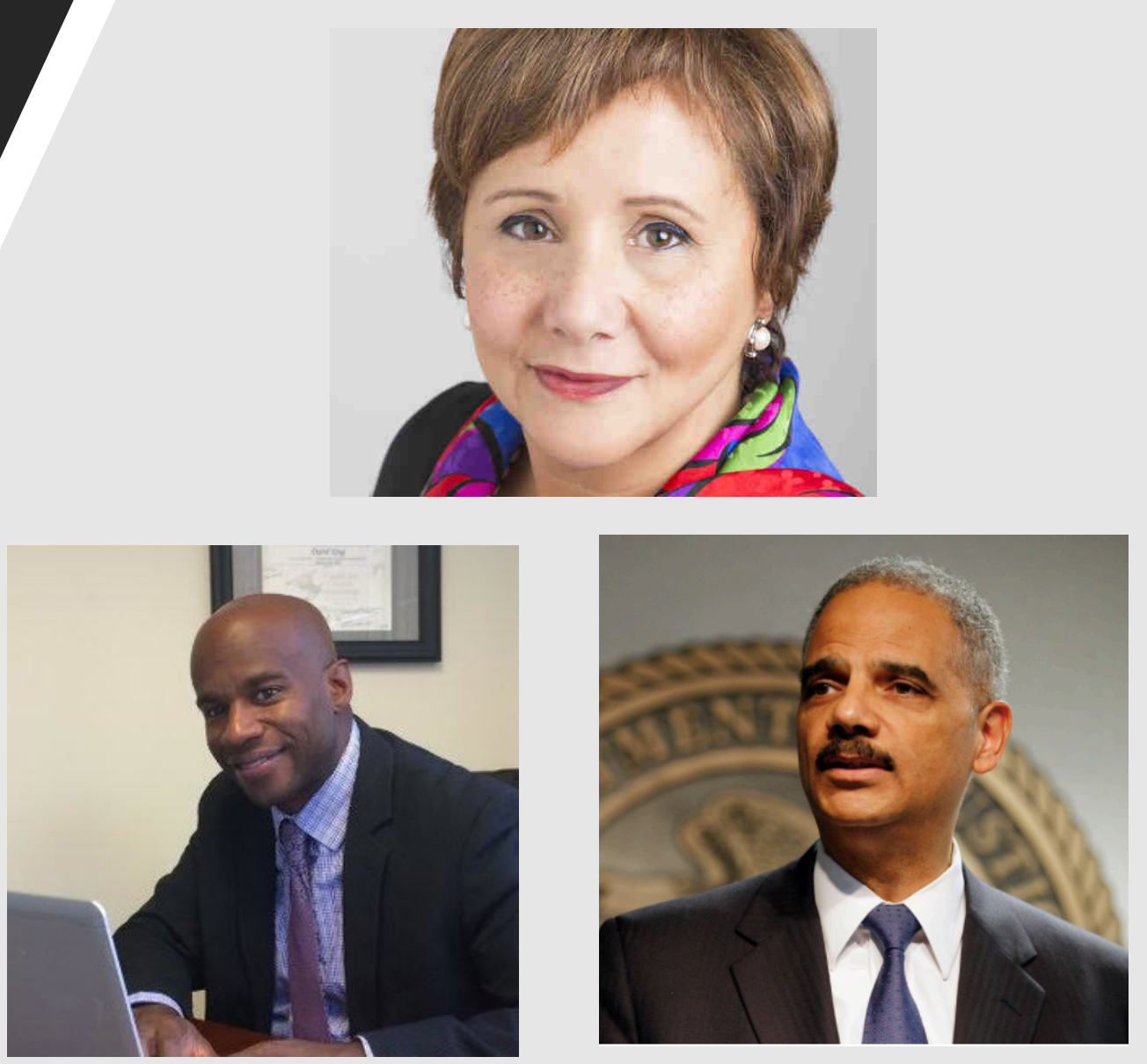


\section{Airbnb's Diversity}

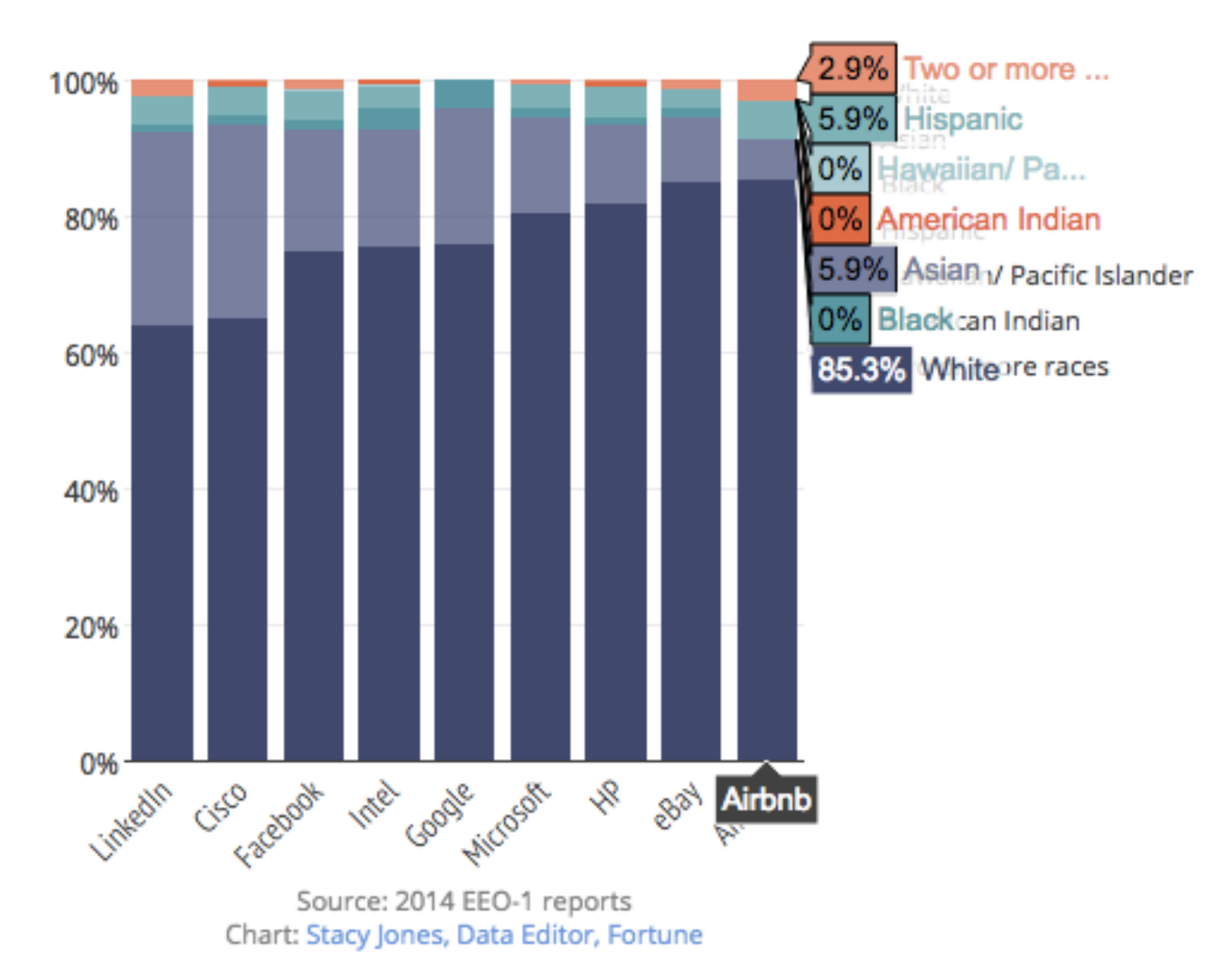




\section{Airbnb's "Community Commitment"}

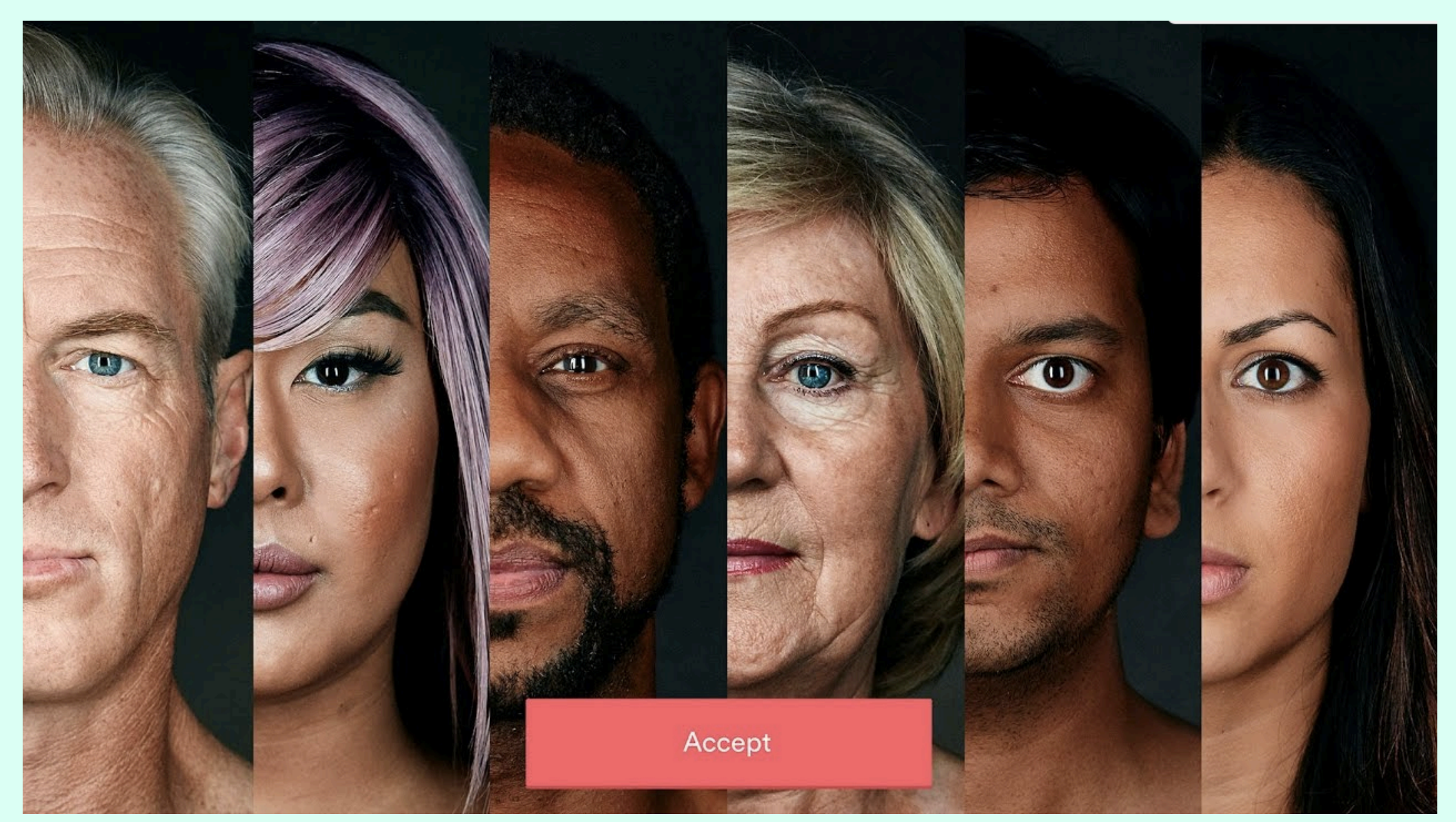




\section{New non-discrimination policy}

Airbnb is, at its core, an open community dedicated to bringing the world closer together by fostering meaningful, shared experiences among people from all parts of the world. Our community includes millions of people from virtually every country on the globe. It is an incredibly diverse community, drawing together individuals of different cultures, values, and norms.

The Airbnb community is committed to building a world where people from every background feel welcome and respected, no matter how far they have traveled from home...

While we do not believe that one company can mandate harmony among all people, we do believe that the Airbnb community can promote empathy and understanding across all cultures. We are all committed to doing everything we can to help eliminate all forms of unlawful bias, discrimination, and intolerance from our platform. ...

We welcome guests of all backgrounds with authentic hospitality and open minds. Joining Airbnb, as a host or guest, means becoming part of a community of inclusion. Bias, prejudice, racism, and hatred have no place on our platform or in our community. 


\section{Gentrification/Affordable Housing}

2008: Great Recession

Airbnb founded

Housing foreclosure: giant wealth transfer

Airbnb keeps housing out of the rental market 


\section{Impact: Gentrification}

\section{New Orleans}

\section{Room Type}

Airbnb hosts can list entire homes/apartments, private or shared rooms.

Depending on the room

type, availability, and

activity, an airbnb listing

could be more like a hotel,

disruptive for neighbors,

taking away housing, and

illegal.

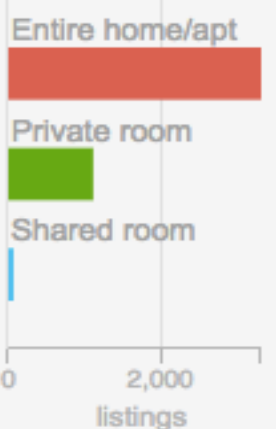

$\square$ Only entire homes/apartments

\section{7\%}

entire homes/apartments

$$
\begin{array}{r}
\$ 187 \\
\text { price/night } \\
3,328(73.7 \%) \\
\text { entire home/apartments } \\
1,117(24.7 \%) \\
\text { private rooms } \\
69(1.5 \%) \\
\text { shared rooms }
\end{array}
$$

\section{Listings per Host}

$\bigcirc$ Only multi-listings

Some Airbnb hosts have multiple listings.

A host may list separate rooms in the same apartment, or multiple apartments or homes available in their entirity.

Hosts with multiple listings are more likely to be running a business, are unlikely to be living in the property, and in violation of most short term rental laws designed to protect residential housing.

49.4\%

multi-listings

$2,283(50.6 \%)$

single listings

$2,231(49.4 \%)$

multi-listings

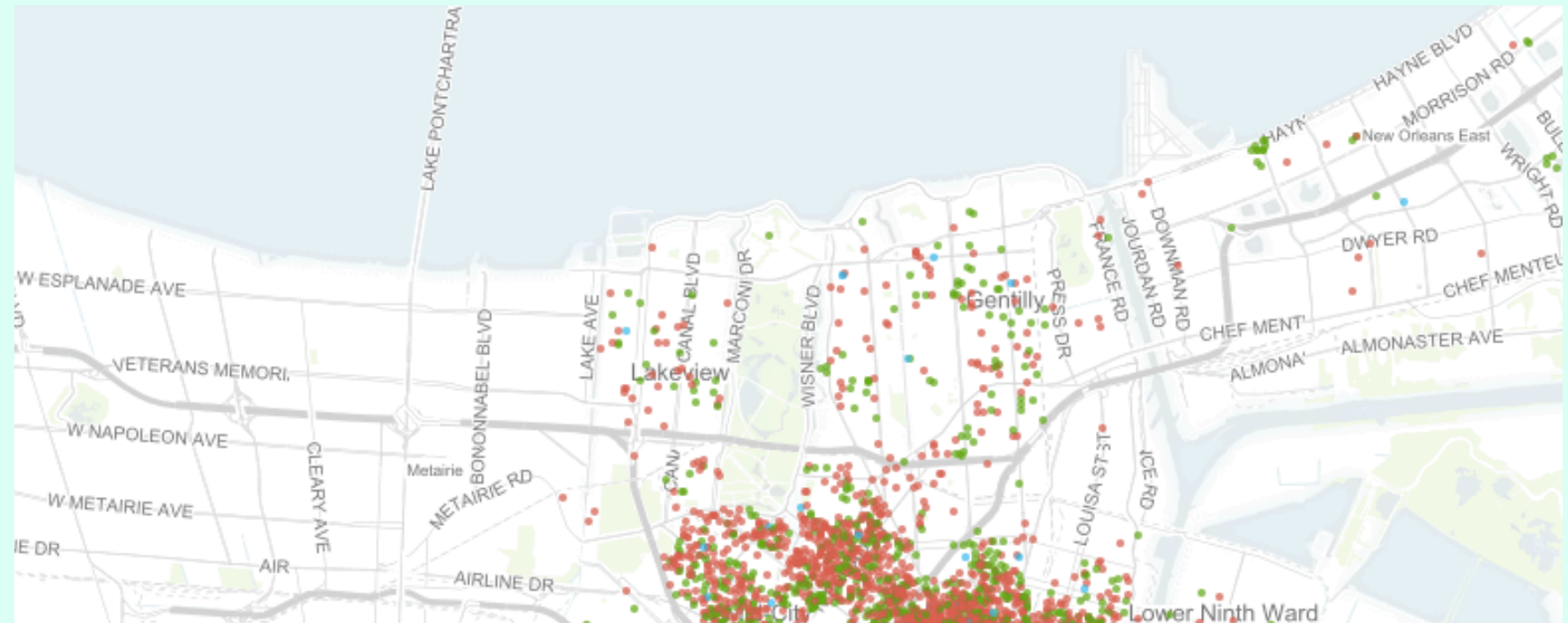

Elmwood
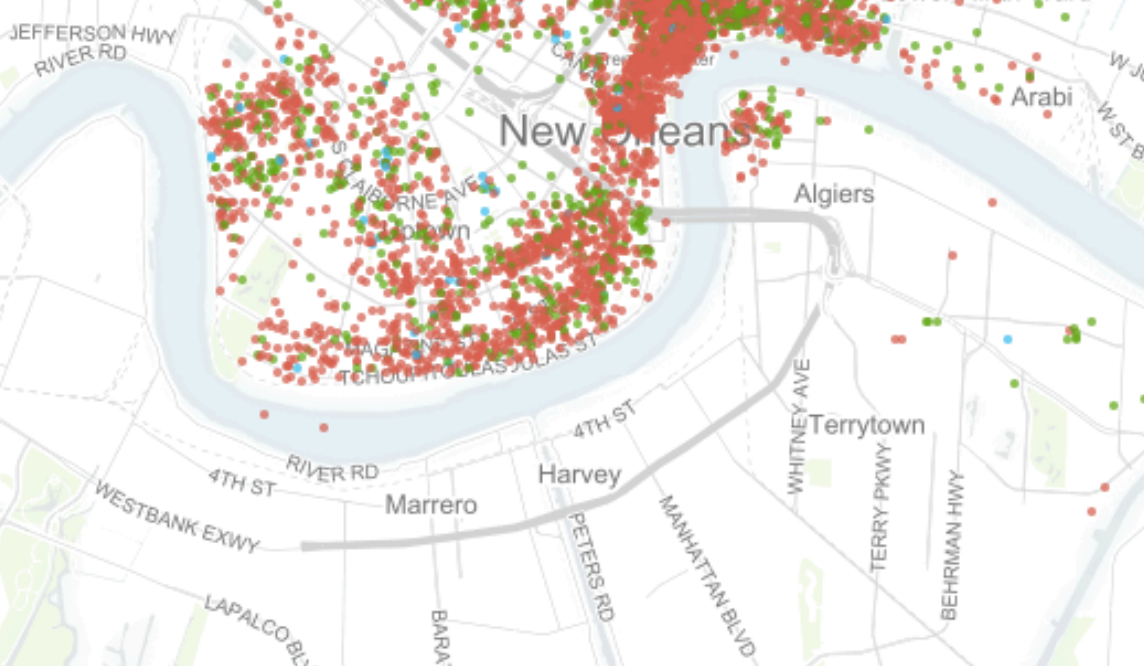


\section{Neighborhood Resistance to Airbnb}

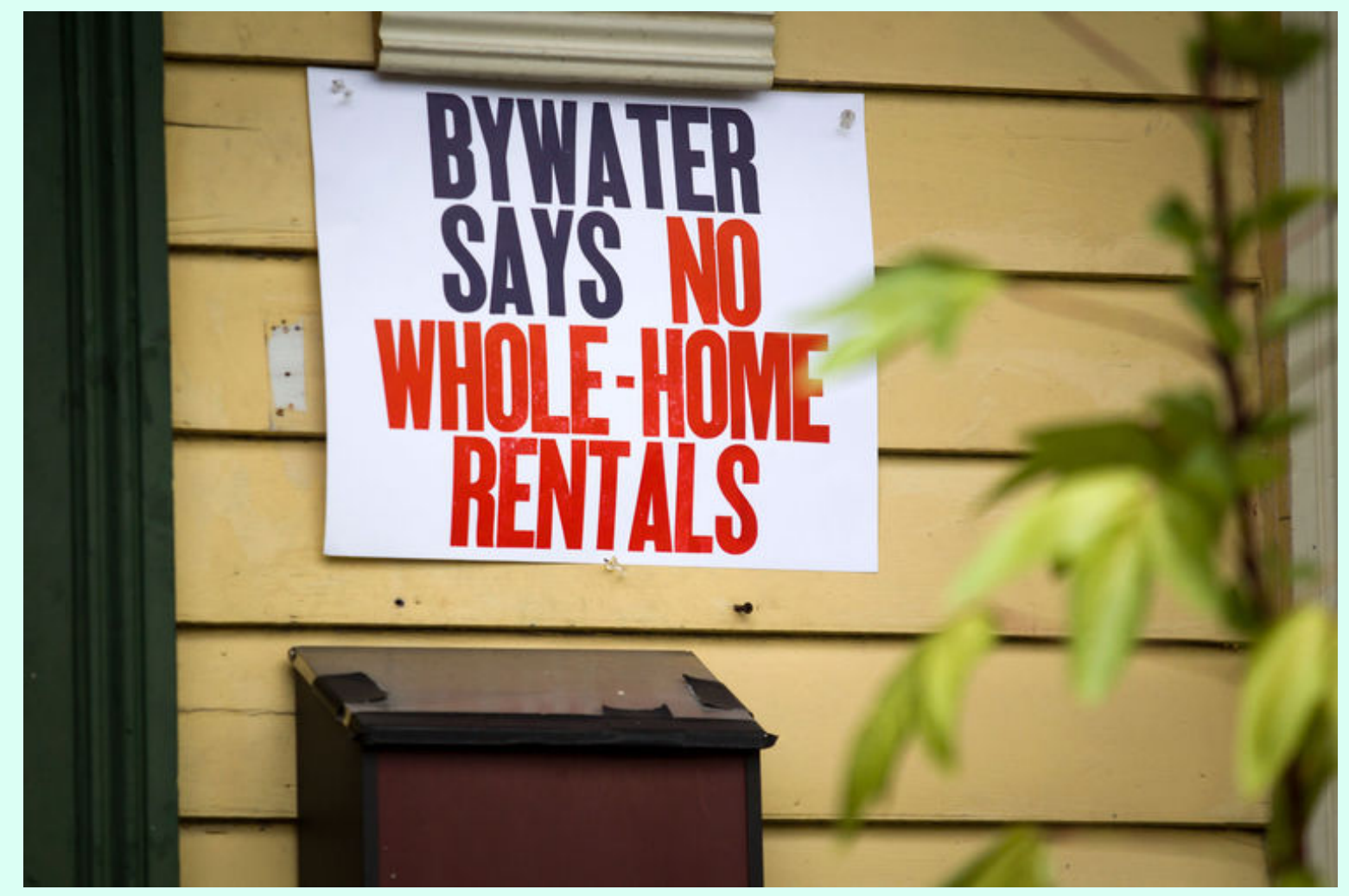

\section{DEAR AIRBNB TOURIST,}

Your vacation/short term rental has led to the eviction of Chinese immigrant families.

We have survived the 1882 Chinese Exclusion Act, 2 World Wars, the 1906 Great Quake and Fires, and the 1989 Earthquake.

But now, our lives, our schools, our grandparents' homes, and social fabric are being destroyed. AIRBNB IS DESTROYING OUR HOME 


\section{Marketing Economic Insecurity}

Q AirbnbAction đairnbbaction - Sep 21 Chekesha, Randy, Kanita, and Synta earn extra income. Learn more about @Airbnb hosts in DC:

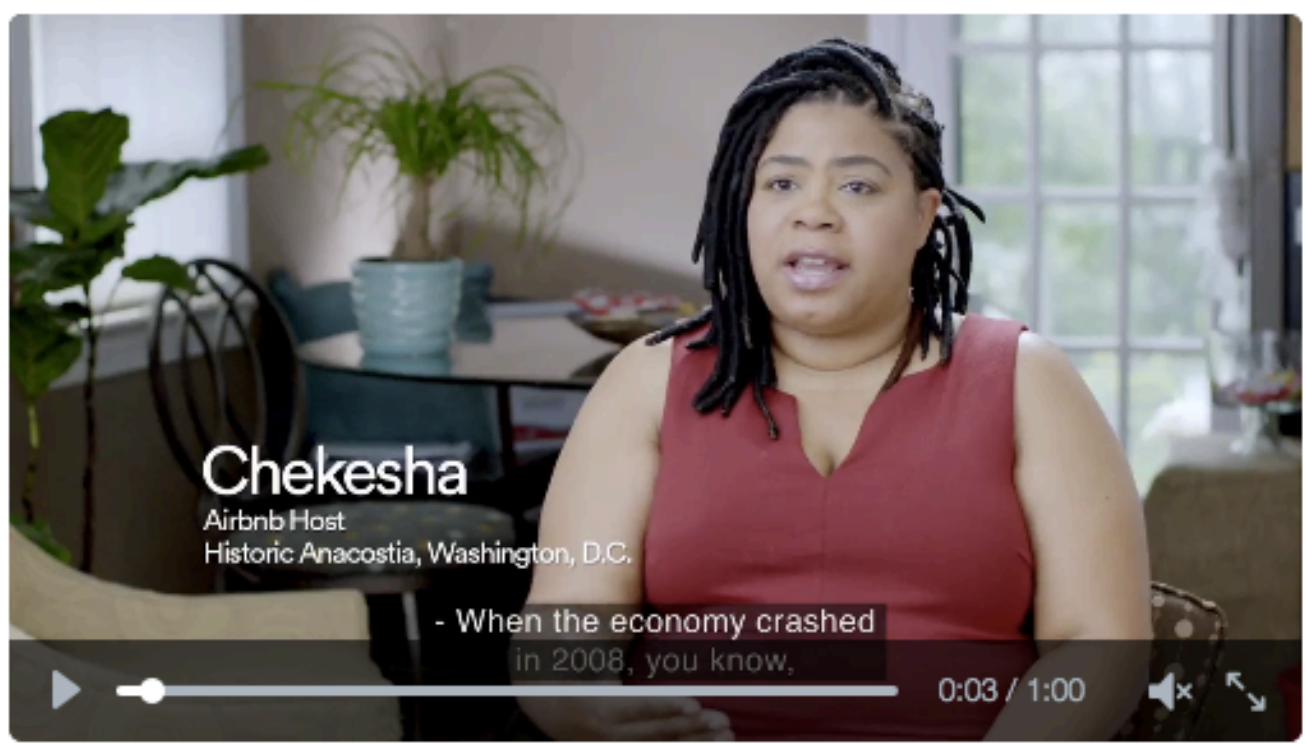

h $27 \begin{array}{lll}4 & 12 & 0\end{array}$ 


\section{Resistance to Regulation}

Enforcing FHA rules

Short-term rental laws/permitting

Hotel taxes

Expects to rewrite law where convenient

Control over data 


\section{Conclusion}

Shaun King EE @Shaunking

Absolutely!

Thank you @Airbnb for leading out front! Love and appreciate you for this strong stance you've taken!

\#WeAccept

Airbnb @ Airbnb

@ShaunKing \#weaccept is more than just a commercial, it's a pledge for us all to stand together.

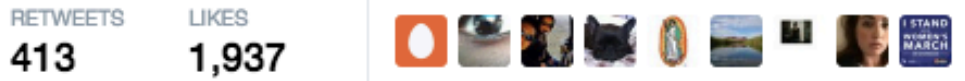

4:47 PM - 5 Feb 2017

4 22 เ7 $413 \bigcirc 1.9 \mathrm{~K}$ 